\title{
Non-intimate Relationships and Psychopathic Interpersonal and Affective Deficits as Risk Factors for Criminal Career: A Comparison Between Sex Offenders and Other Offenders
}

\section{OPEN ACCESS}

Edited by:

Noora Ellonen,

University of Tampere, Finland

Reviewed by:

Matt DeLisi,

lowa State University, United States

Richard S. John,

University of Southern California,

United States

Laura Jayne Broome,

Swansea University, United Kingdom

${ }^{*}$ Correspondence:

Fulvio Carabellese carabellese.fulvio@gmail.com

Specialty section:

This article was submitted to Forensic and Legal Psychology, a section of the journal

Frontiers in Psychology

Received: 29 August 2020 Accepted: 03 August 2021

Published: 24 August 2021

Citation:

Ferretti F, Pozza A, Carabellese F,

Schimmenti A, Santoro $G$,

Mandarelli G, Gualtieri G,

Carabellese F, Catanesi $R$ and

Coluccia A (2021) Non-intimate

Relationships and Psychopathic

Interpersonal and Affective Deficits as

Risk Factors for Criminal Career:

A Comparison Between Sex

Offenders and Other Offenders.

Front. Psychol. 12:600370.

doi: 10.3389/fpsyg.2021.600370

\section{Fabio Ferretti ${ }^{1}$, Andrea Pozza ${ }^{1}$, Fulvio Carabellese ${ }^{1 *}$, Adriano Schimmenti ${ }^{2}$, Gianluca Santoro ${ }^{2}$, Gabriele Mandarelli ${ }^{3}$, Giacomo Gualtieri' ${ }^{1}$, Felice Carabellese ${ }^{3}$, Roberto Catanesi $^{3}$ and Anna Coluccia ${ }^{1}$}

${ }^{1}$ Department of Medical Sciences, Surgery and Neurosciences, University of Siena, Siena, Italy, ${ }^{2}$ Kore University of Enna, Enna, Italy, ${ }^{3}$ Forensic Psychiatry, University of Bari, Bari, Italy

Sex-offenders are at risk of criminal recidivism. For the treatment to be truly effective, it must be individualized. For this purpose, an accurate assessment should focus on criminological, psychological, and psychopathological features. The present study compared sex offenders with other offenders on historical experiences (i.e., problems with violence, anti-social behaviors, problems with personal relationships, problems with substance use, traumatic experiences, and parenting style). In addition, given the association between life events and psychopathy, we explored whether the relation between life events and crime type (sexual crime vs. other types of crime) might be moderated by psychopathy traits (interpersonal and affective deficits and antisocial behavior). Eighty-eight sex offenders (76\% of whom child molesters) and 102 other offenders were included. The Historical, Clinical and Risk Management - 20 item Version 3 (HCR-20V3) and Psychopathy Checklist-Revised (PCL-R) were administered. The scores of the HCR-20V3 Historical scale items were computed to assess life events. The scores of the PCL-R factors, F1 Interpersonal affective deficits and F2 Antisocial behavior, were recorded. The presence of a history of problems with non-intimate relationships was the only significant risk factor for sexual crime compared with other crimes. Interpersonal and affective deficits provided an increased likelihood of being sex offenders as compared with other offenders when problems with non-intimate relationships were possibly/partially or certainly present.

Keywords: sex offenders, risk factors, psychopathy, personality traits, life events

\section{INTRODUCTION}

The history of criminal perpetrators, the developmental pattern of their careers, and the risk factors for criminal behaviors have always been considered a central topic in criminological research.

The relationship between the traumatic experiences of the sexually abused victims and the arising of dysfunctional sexual behaviors was investigated by several scholars, with the conclusion 
that additional causes underlying sexual offenses must be searched and that the so-called Victim/Perpetrator Paradigm is too reductive (Burton, 2008; Rasmussen, 2012).

Psychiatric disorders play an important role as well. Schizophrenia and bipolar disorder (Carabellese et al., 2012; Pozza et al., 2019, 2020) and mood and personality disorders (Dunsieth et al., 2004; Coluccia et al., 2020) were detected in sex offenders. In their research on a sample of 1346 sex offenders, Eher et al. (2019) found that 50.1\% of them suffered from personality disorders. Carabellese et al. (2012) confirmed these results, highlighting the role of schizoid, narcissistic, and avoidant personality disorders.

The relevance of psychopathy on criminal behavior and violent conduct is widely recognized in the literature, and it is generally assessed by the gold standard measure Psychopathy Checklist-Revised (PCL-R; Hare and Neumann, 2006) which covers two main factors, i.e., interpersonal and affective deficits and antisocial behavior (Carabellese et al., 2008; Leistico et al., 2008; Campbell et al., 2009; Campobasso et al., 2009; Kennealy et al., 2010; Yang et al., 2010; Ismail and Looman, 2018; Mazzoni et al., 2018). The association between psychopathy and sexual crimes emerged in several studies, including a meta-analysis conducted by Hanson et al. (2009) which found that the presence of psychopathy in sex offenders constitutes a predictive factor for criminal recidivism in sexual offenses and other types of offenses. High scores on the PCL-R were found to be associated with experiences of neglect and abuse (Kimonis et al., 2011; Schraft et al., 2013; Ometto et al., 2016; Sevecke et al., 2016). Other studies (e.g., Schimmenti et al., 2020) have shown that the relational failure of caregivers in the attachment system, due to experiences of neglect, early abandonment or loss of caregivers, can lead the child to difficulty in interpersonal self-regulation skills. These interpersonal difficulties can in turn represent a risk factor in adults for aggressive behavior, difficulties in emotion regulation and sexual problems, as it can be found in many cases of psychopathy, sadism, or paraphilia.

Such a kaleidoscope of different situations makes it difficult to identify those risk factors that can affect the dysfunctional sexual behavior of sex offenders. Due to the variety of factors that must be considered when studying sexual crimes, investigating sex offenders' criminal career through different risk factors is a topic that still deserves the attention of researchers. Although the evidence about these relationships is still controversial, at least partly, sex offenders seem to show a higher prevalence of physical, sexual, and emotional abuse during their childhood (Lee et al., 2002; Jespersen et al., 2009; Seto and Lalumière, 2010; Drury et al., 2019) and a history of family dysfunctions (Lee et al., 2002), poor parenting style (Sigre-Leirós et al., 2016) and symptoms of social anxiety (Porter et al., 2015). In their review, Kraanen and Emmelkamp (2011) reported that sex offenders' criminal career is associated with substance abuse, alcohol, and drug misuse.

Among the psychometric instruments for professional risk assessment, the Historical, Clinical and Risk Management - 20 item Version 3 (HCR-20 Version 3; Douglas et al., 2013) represents a psychometrically sound instrument, designed to give a comprehensive framework for the entire process of risk assessment (Douglas et al., 2013). The historical items of the HCR-20V3 provide a series of information on the subject's existential path. The items recall some factors among those mentioned (items $\mathrm{H} 1, \mathrm{H} 2, \mathrm{H} 3, \mathrm{H} 5, \mathrm{H} 8$ ) that could have a significant role in the criminal career. Moreover, the historical items of HCR-20V3 take into consideration other factors, in particular personality disorders (H7) and major mental disorders (H6). In addition to being correlated with violent behavior (Carabellese et al., 2020a) and sexual offenses (Somma et al., 2020), such disorders can interact with the psychopathic dimension (Wong and Olver, 2016), another personality factor notoriously correlated with the risk of criminal recidivism (Hanson and Morton-Bourgon, 2005). Cartwright et al. (2018) suggested that the HCR-20V3 plays an important role in the assessment and management of sex offenders beyond the assessment of the risk of relapse. The HCR-20V3 has proved to be a valid predictor of violent conduct in perpetrators of crimes, and its use as a predictive tool has also been suggested in sex offenders (Cartwright et al., 2018). The factors that the HCR$20 \mathrm{~V} 3$ takes into consideration, especially in the historical items, represent a valid support for a professional judgment aimed to develop a personalized therapeutic project (Yates, 2013; Gannon et al., 2019).

The aim of this study was to explore the relevance of life events in criminal outcome, comparing sex offenders with other offenders about historical experiences assessed by the HCR$20 \mathrm{~V} 3$ related to problems with violence, anti-social behaviors, problems with personal relationships, problems with substance use, traumatic experiences, and parenting style. This is the first study which explored risk factors in sex offenders by using HCR-20V3 in its validated Italian version (Caretti et al., 2019) and one of the few studies which investigated the discriminant role of these life events comparing sex offenders (SO) with other offenders (OO). In addition, given the association between life events and psychopathy, we explored whether the relation between certain life events measured by the HCR-20 V3 and the type of crime (sexual crime vs. other types of crime) might be moderated by psychopathy traits, i.e., interpersonal and affective deficits and antisocial behavior.

\section{MATERIALS AND METHODS}

\section{Participants and Setting}

This research is part of a national multicenter project authorized by the Penitentiary Administration Department of the Ministry of Justice. The study was reviewed and approved by the Director and ethical board of Penitentiary Administration Department of Ministry of Justice in accordance with the current ethical standards and in compliance with the rules concerning the privacy of data related to the perpetrators of sexual crimes. This multicenter study was realized with the collaborations of the penitentiary institutions of six Italian regions (Lombardia, Veneto, Toscana, Lazio, Puglia e Sicilia). The regions involved were chosen for the presence of university centers that planned the enrollment of the sample, the collection and analysis of the data. The researchers had previously been trained in the use of the tools. All the prisoners enrolled in the study received 
a final conviction for their crimes. Data were collected during 2015 and 2016 and only the prisoners who had previously given their consent to meet the researchers were included in the study. For legal and privacy-related reasons, data will not be made available.

The exclusion criteria were applied to both the SO and the OO groups and consisted of the lack of provision of the informed consent and the presence of a lifetime psychiatric diagnosis which was considered by the Penitentiary Administration an exclusion criterion to prevent the fact that the relation between life events and sexual crime might be attributed to a psychiatric history as psychiatric disorders are observed in sex offenders (Dunsieth et al., 2004; Carabellese et al., 2012; Eher et al., 2019). The presence of a lifetime psychiatric diagnosis was established by the penitentiary administration if the individual had received or was receiving a psychiatric treatment, i.e., psychiatric medications or psychotherapeutic treatments prescribed or delivered by a mental health professional in any period during his life.

In Italy, the number of sexual offenses leading to the internment of the offenders in the so-called High-Security Forensic Psychiatry Residences (i.e., the psychiatric facilities hosting socially dangerous offenders with a mental disorder) is relatively low (3.4\%) (Catanesi et al., 2019). As for the sex offenders with mental disorders not serious enough to exclude criminal responsibility, in Italy they are sentenced in prison, but in this case, we had no data concerning them because the prisoners with psychiatric disorders were excluded from the study by the Penitentiary Administration.

Eighty-eight SO and $102 \mathrm{OO}$ were assessed by researchers trained in the administration of the tools, to guarantee uniformity and homogeneity in data collection. The category SO was declined according to the definition given by Myers et al. (2005), even though the majority (76\%) of these inmates were child molesters. The final sample of 88 sex offenders did not commit any other crimes than sexual offenses, possibly in relapse. The data concerning the fact that the SOs had been convicted for the first time or they were recidivists, though, was kept confidential by the prison management. It must also be said that SOs in Italy are either detained in separate prisons (as happens for example in Puglia), or they are placed in special sections within the individual prisons.

The category $\mathrm{OO}$ included a heterogeneous set of crimes, such as personal crimes (homicide, assault), property crimes (robbery, fraud), and crimes against the State, but not sex offenses.

A preliminary meeting with prisoners and social workers was scheduled before the assessment, to present the research project and collect participants' written consent (Mandarelli et al., 2017). At this stage, about $18 \%$ of prisoners refused to give informed consent and participate. However, the researchers did not know the number of those who had initially refused to participate to the preliminary meeting in which the project was presented. In fact, the request as to whether the prisoners intended to participate to the preliminary meeting had been made by the penitentiary institutions and kept confidential. The various stages of sample recruitment are shown in Supplementary Material.

\section{Measures}

The Psychopathy Checklist-Revised (PCL-R; Hare and Neumann, 2006) in its validated Italian version (Caretti et al., 2011) was administered to assess the presence of psychopathy. PCL-R factor 1 captures traits dealing with the interpersonal and affective deficits of psychopathy (e.g., shallow affect, superficial charm, manipulativeness, and lack of empathy), whereas factor 2 deals with symptoms relating to antisocial behavior (e.g., criminal versatility, impulsiveness, irresponsibility, poor behavior controls, and juvenile delinquency) (Hare et al., 1989). The scores of the two different components of factors F1 and F2 were recorded, as well as the values of the different components within factors F1 and F2. A threshold score of PCL-R equal to or greater than 25 was established to identify the condition of psychopathy, as indicated in studies conducted on European populations (Grann et al., 1998; Andersen et al., 1999; Jüriloo et al., 2013).

The HCR-20V3 Italian version (Douglas et al., 2013; Caretti et al., 2019), a tool assessing the risk of violence, was administered. Some items of the Historical Scale were considered to analyze the existence of lifetime problematic experiences that can be considered risk factors for the development of sexually based crimes. According to the literature about risk factors for sex offending, the following items were selected among those belonging to the Historical Scale: (a) H1 - problems with violence; (b) H2 - problems with other antisocial behavior; (c) H3 - problems with relationships; (d) H5 - problems with substance use; (e) H8 - problems with traumatic experiences. Items $\mathrm{H} 1$ and $\mathrm{H} 2$ are divided in sub-items expressing three age classes: (1) child, 12 years and younger; (2) adolescent, 1317 years; (3) adult, 18 years and older. The item $\mathrm{H} 3$ is divided in two sub-items (intimate and non-intimate relationships), and the item $\mathrm{H} 8$ is also divided in two sub-items (victimization/trauma and adverse child rearing experiences). Every item is scored 0 , 1, or 2: 0 if the item is definitely absent, 1 if the item possibly is present, or present to a minor/moderate degree, and 2 if the item is definitely present. All the researchers involved had been trained through role-playing and internships to administer the tools before the research was initiated.

Together with the assessment scales, the anamnestic and criminological data were collected through the examination of the personal data sheets.

\section{Statistical Analysis}

Descriptive statistics were used to describe subjects' characteristics (mean and standard deviation for continuous measures, frequencies, and relative frequencies for categorical variables). In accordance with the manual of the instrument (Caretti et al., 2019), the presence of the risk factors was measured by the HCR20V3 Historical item scores which were coded as a categorical variable (i.e., response categories: "No" vs. "Possibly/Partially" vs. "Yes").

The characteristics of incarcerated groups (SO vs. OO) and their risk factors assessed with HCR-20V3 were compared using parametric tests for the continuous variables (Student's $t$-test, 
once verified the assumption of normality with KolmogorovSmirnov test) and non-parametric tests for categorical variables (Chi-square and Fisher's Exact Test).

A binary logistic model was used to estimate the effect of the HCR-20V3 historical risk factors in predicting criminal careers, with being SO or $\mathrm{OO}$ as the dichotomous dependent variable. Only those risk factors that showed a significant difference in the comparison of the two groups were included as predictors in the regression model. The assumptions related to the sample size adequacy, the independence of observations, and the lack of multicollinearity among the independent variables were verified. Model fit was assessed through Hosmer-Lemeshow test. The Wald's statistic was used to analyze the predictors' contribution to the explanation of the dependent variable. The Odds Ratio and their 95\% confidence intervals were computed for each predictor's category. A second binary logistic model was fitted to assess the interaction effects with PCL-Rs' Factors 1 and 2 .

Data analysis was performed with SPSS-IBM v25 software, setting significance at $p<0.05$.

\section{RESULTS}

Table 1 summarizes the characteristics of the two groups of subjects (SO vs. OO). The total mean age was $45.12 \pm 12.732$, and it was significantly higher in the SO group $\left(t_{(188)}=-3.947 ; p=0.000\right)$. About half of the convicted was unemployed (46.8\%), and a percentage of $11.1 \%$ showed a diagnosis of psychopathy (PCL$\mathrm{R}$ score $\geq 25$ ). No association was found between the employment status, or the diagnosis of psychopathy, and the two groups of subjects.

Considering the educational attainment, the secondary school was the most frequent (41.1\%), followed by high school (38.4\%). A higher school level was associated with the SO group $\left(\chi^{2}(3)=24.186 ; p=0.000\right)$. Chi-Square post hoc tests were performed by checking the significance of the adjusted residuals of the contingency table cells, with Bonferroni correction. The results of the post hoc tests showed that SO and OO groups showed significant adjusted residuals for secondary school and university degree (both, respectively: $p=0.022$ and $p=0.001)$.

The results of the comparisons on the HCR-20 V3 between $\mathrm{SO}$ and $\mathrm{OO}$ on the risk factors carried out by non-parametric tests are presented in Table 2. Post hoc analysis results are displayed in the note of Table 3 . Some of the risk factors assessed as definitely present (coded as "Yes") showed a high prevalence in the total group of subjects. A history of problems with violence as an adult (18 and over) was detected in the $62.1 \%$ of subjects, and problems with antisocial behavior, once again as an adult, pertained to the $46.3 \%$ of the prisoners enrolled in the study. Problems with relationships showed a high prevalence in this sample, intimate and non-intimate as well (respectively: 47.9 and 35.8\%). A history of problems with substance use was definitely found in the $34.2 \%$ of the subjects, whilst risk factors related to traumatic experiences were detected in a lower proportion: $30.0 \%$ experienced a victimization or trauma, and $26.8 \%$ reported experiences of adverse child rearing.

Six out of eleven risk factors considered in the analysis displayed a significant association with the groups: $(a, b)$ problems with violence (as a child and as an adult), (c,d) problems with other antisocial behavior (as a child and as an adult), (e) problems with non-intimate relationships and (f) problems with substance use. Prisoners included in the OO group seemed to be portrayed by a history of problems with violence. Considering the subscale "as an adolescent (13-17)" and summing the relative frequencies of the two categories "Possibly/Partially" or "Yes", this risk factor was observed in the $47.1 \%$ of the OO group, against the $19.4 \%$ of the SO group $\left(\chi^{2}(2)=19.285 ; p=0.000\right)$. Although a history of problems with violence as an adult was more frequent in the SO group than in the OO group (respectively: 65.9 and $58.8 \%$ ), the lack of this risk factor proved to be double than that of the OO group (respectively: 20.5 and $11.8 \% ; \chi^{2}{ }_{(2)}=7.960$; $p=0.019)$. Also the other antisocial behaviors characterized the OO group: during the adolescence, this problem was detected ("Possibly/Partially" or "Yes") in the $56.8 \%$ of the OO group $\left(S O=27.2 \% ; \chi^{2}(2)=17.288 ; p=0.000\right)$, and, as an adult, this percentage was $77.4 \%\left(S O=50.0 \% ; \chi^{2}(2)=16.615 ; p=0.000\right)$. The last risk factor associated with the OO group concerned substance use $\left(\chi^{2}(2)=25.697 ; p=0.000\right)$.

Finally, a history of problems with non-intimate relationships was the only risk factor linked to the criminal career of the SO: in this group, it was definitely assessed in the $43.2 \%$ of the subjects, against the $29.4 \%$ of the OO group $\left(\chi^{2}(2)=7.416 ; p=0.025\right)$.

The results of Student's $t$-tests showed that as compared with OO, the group of SO had significantly higher and lower scores, respectively, on the PCL-R F1 Interpersonal and Affective Deficits and PCL-R F2 Antisocial Behavior. In both groups, the scores on the PCL-R factors were moderately correlated to each other. The results of the comparisons on the PCL-R factor scores and the correlations in the two groups are presented in Supplementary Material.

These six mentioned factors presenting a significant association with the study groups were included as predictors in a binary logistic regression model. The results of the logistic regression analysis are presented in Table 3 where the role of HCR-20V3 historical risk factors is entered as predictors and the criminal career (defined as being a SO or OO) is entered as dichotomous outcome. The lack of significance of the HosmerLemeshow test $\left(\chi^{2}{ }_{(8)}=7.078 ; p=0.528\right)$ proved the goodness of the model fitting. The percentage of predicted cases was $73 \%$ out of the total group.

Three risk factors did not show a significant contribution to the dependent variable: problems with violence (as an adult) and problems with antisocial behavior (as an adolescent and as an adult).

Two risk factors provided a significant effect on the dependent variable but in favor of the "other offenders" criminal career: the possible, or partial, presence of problems with violence as an adolescent $\left(\beta=-1.237\right.$; Wald's $\left.\chi^{2}(1)=5.090 ; p=0.024\right)$ and the certain history of substance use $(\beta=-1.615$; Wald's $\left.\chi^{2}(1)=11.092 ; p<0.001\right)$. According to these results, the 
TABLE 1 | "Sex Offenders" (SO) and "Other Offenders" (OO) characteristics: age, employment status, educational attainment, and diagnosis of psychopathy.

\begin{tabular}{|c|c|c|c|c|c|c|}
\hline & & Total & SO $(n=88)$ & O० (n = 102) & Statistic & $p$ \\
\hline Age (mean $\pm \mathrm{SD}$ ) & & $45.12 \pm 12.732$ & $48.90 \pm 13.281$ & $41.85 \pm 11.232$ & $t_{(188)}=-3.947$ & 0.000 \\
\hline \multirow[t]{2}{*}{ Employment status n.(\%) } & Employed & $101(53.2)$ & $50(56.8)$ & $51(50.0)$ & Fisher's Exact Test & 0.383 \\
\hline & Unemployed & $89(46.8)$ & $38(43.2)$ & $51(50.0)$ & & \\
\hline \multirow[t]{4}{*}{ Educational attainment $n .(\%)$} & Primary school & $13(6.8)$ & $2(2.3)$ & $11(10.8)$ & $x^{2}(3)=24.186$ & 0.000 \\
\hline & Secondary school & $78(41.1)$ & $26(29.5)$ & $52(51.0)$ & & \\
\hline & High school & $73(38.4)$ & $39(44.3)$ & $34(33.3)$ & & \\
\hline & University degree & $26(13.7)$ & $21(23.9)$ & $5(4.9)$ & & \\
\hline \multirow[t]{2}{*}{ Diagnosis of psychopathy (PCL-R $\geq 25) n .(\%)$} & Yes & $21(11.1)$ & $9(10.2)$ & $12(11.8)$ & Fisher's Exact Test & 0.819 \\
\hline & No & 169 (88.9) & 79 (89.8) & $90(88.2)$ & & \\
\hline
\end{tabular}

Bold values represent statistically significant $p$-values.

detection of these risk factors was associated with a lower likelihood of being "SO".

The presence of a history of problems with non-intimate relationships was the only significant risk factor explaining the outcome "SO". The high value of the Wald's statistic (6.325) expressed its relevant contribution to the regression model. Looking at the odds ratio, the prisoners experiencing problems with non-intimate relationships were 3.610 (95\% CI 1.327-9.819) times more likely to be a "SO" than another type of offender.

Although no significant difference was found between SO and $\mathrm{OO}$ on their psychopathological conditions, a second logistic regression was estimated, using the only significant predictor for the SO category in interaction with the two PCL-R factors: (F1) interpersonal and affective deficits, (F2) antisocial behavior. The results of the logistic regression analysis are shown in Table 4 where the interaction effects between the significant risk factor (i.e., Non-Intimate Relationships) and the two PCL$\mathrm{R}$ factors (i.e., Interpersonal and Affective Deficits and Antisocial Behavior, respectively) were included as predictors and the sexual career (i.e., being a SO vs. OO) is included as dichotomous outcome. The lack of significance of the Hosmer-Lemeshow test $\left(\chi^{2}{ }_{(6)}=2.896 ; p=0.822\right)$ confirmed the goodness of fit, even if the percentage of predicted cases was quite low ( $66 \%$ out of the total group). In other words, a $29 \%$ of the variance between the SO and OO groups was attributed to the psychopathy factors when we considered problems with nonintimate relationships.

Both PCL- $R$ factors showed a significant interaction with the existence of problems with the non-intimate relationships detected with HCR-20 V3, but with opposite effects. Increasing values of the PCL-R Factor 1 (interpersonal and affective deficits) provided an increased likelihood of being SO when problems with the non-intimate relationships were possibly/partially or certainly present ("Possibly/partially": $\beta=0.358$, Wald's $\chi^{2}{ }_{(1)}=9.493, p=0.002$; "Yes": $\beta=0.251$, Wald's $\chi^{2}{ }_{(1)}=10.824$, $p=0.001)$. On the contrary, increasing values of the PCL-R Factor 2 (antisocial behavior) were associated to a decreased likelihood of being SO when problems with the non-intimate relationships were possibly/partially or certainly present ("Possibly/partially": $\beta=-0.533$, Wald's $\chi^{2}(1)=13.396, p=0.000$; “Yes": $\beta=-0.231$, Wald's $\left.\chi^{2}(1)=10.291, p=0.001\right)$.

\section{DISCUSSION}

The challenge of this study was to border the investigation concerning the association between risk factors and criminal career, to the identification of those lifetime events that can discriminate sex offenders from other offenders. The risk factors were assessed by a set of items of the HCR-20 V3 Historical scale. As compared with the $\mathrm{SO}$, the $\mathrm{OO}$ group showed a greater likelihood of having a history of problems with violence and antisocial behavior (as adolescents and adults), together with problems with substance abuse. These findings were in line with the literature evidence. Only one risk factor, i.e., the presence of problems in non-intimate relationships, discriminated the criminal career of sex offenders from other types of criminals. In the HCR-20 V3 manual, non-intimate relationships are depicted as the bonds with the family members, the friends, or with generic acquaintances which do not involve the sexual dimension. Social isolation, emotional distance, instability or conflict, manipulation of others, inappropriate sexualization and violence in nonintimate relationships and escalation of problems are indicators of the presence of such problems. As compared with the OO group, SO showed higher and lower levels, respectively, of psychopathic interpersonal and affective deficits and antisocial behavior. Finally, the present findings confirmed the importance of deficient non-intimate relationships in predicting the criminal career of sex offenders.

Furthermore, this association was boosted by psychopathic traits related to interpersonal and affective deficits, but not by antisocial behavior. The moderator role of interpersonal/affective deficits in the relation between problems in non-intimate relationships and the risk of being $\mathrm{SO}$ vs. OO seems to be partially in line with a meta-analysis which indicates that this psychopathy facet is associated with violence (Kennealy et al., 2010). The present findings suggest that during clinical practice the assessment of SO should focus on social isolation, 
TABLE 2 | Comparison among "sex offenders" (SO) and "other offenders" (OO) about the risk factors assessed with HCR-20-historical scale (items: H1a, H1b, H1c, H2a, H2b, H2c, H3a, H3b, H5, H8a, H8b).

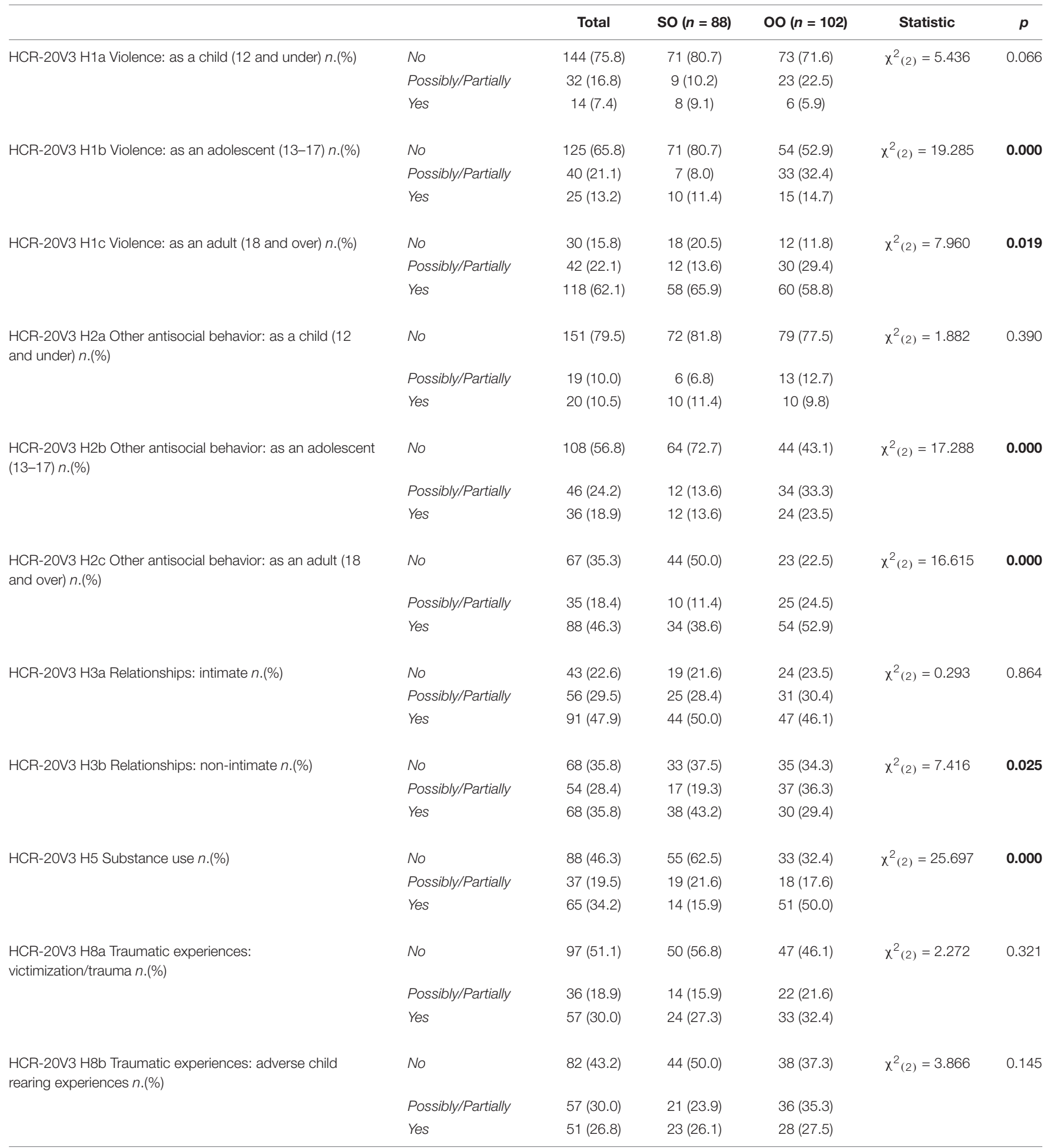

Post hoc tests and the significance of the standardized adjusted residuals ( $n s=$ not significant).

a: No-SO: $p=0.000$; No-OO: $p=0.000$; Possibly/Partially-SO: $p=0,000$; Possibly/Partially-OO: $p=0,000$; Yes-SO =ns; Yes-OO =ns.

b: No-SO: $p=n s ;$ No-OO: $p=n s ;$ Possibly/Partially-SO: $p=n s ;$ Possibly/Partially-OO: $p=n s ;$ Yes-SO: $p=n s ;$ Yes-OO: $p=n s$.

c: No-SO: $p=0.000$; No-OO: $p=0.000$; Possibly/Partially-SO: $p=0,008 ;$ Possibly/Partially-OO: $p=0,000 ;$ Yes-SO: $p=n s ;$ Yes-OO: $p=n s$.

d: No-SO: $p=0.001$; No-OO: $p=0.001$; Possibly/Partially-SO: $p=n s ;$ Possibly/Partially-OO: $p=n s ;$ Yes-SO: $p=n s ;$ Yes-OO: $p=n s$.

e: No-SO: $p=n s ;$ No-OO: $p=n s ;$ Possibly/Partially-SO: $p=n s ;$ Possibly/Partially-OO: $p=n s ;$ Yes-SO: $p=n s ;$ Yes-OO: $p=n s$.

f: No-SO: $p=0.000$; No-OO: $p=0.000$; Possibly/Partially-SO: $p=n s ;$ Possibly/Partially-OO: $p=n s ;$ Yes-SO: $p=0.000 ;$ Yes-OO: $p=0.000$.

Bold values represent statistically significant $p$-values. 
TABLE 3 | Results of the binary logistic model fitting: predictive effects of HCR-20V3 Historical items.

\begin{tabular}{|c|c|c|c|c|c|c|c|}
\hline \multirow[t]{2}{*}{ Predictors } & \multirow[t]{2}{*}{$\beta$} & \multirow[t]{2}{*}{ S.E. } & \multirow[t]{2}{*}{ Wald's statistic } & \multirow[t]{2}{*}{$p$} & \multirow[t]{2}{*}{ OR } & \multicolumn{2}{|c|}{ OR $95 \% \mathrm{Cl}$} \\
\hline & & & & & & $\begin{array}{l}\text { Lower } \\
\text { limit }\end{array}$ & $\begin{array}{c}\text { Upper } \\
\text { limit }\end{array}$ \\
\hline \multicolumn{8}{|l|}{ HCR-20V3 H1b Violence: as an adolescent (13-17) } \\
\hline Violence: (13-17) - No & & & Wald's $\chi^{2}(2)=5.100$ & 0.078 & & & \\
\hline Violence: (13-17) - Possibly/Partially & -1.237 & 0,548 & Wald's $\chi^{2}(1)=5.090$ & 0.024 & 0.290 & 0.099 & 0.850 \\
\hline Violence: $(13-17)$ - Yes & -0.389 & 0.617 & Wald's $\chi^{2}(1)=0.398$ & 0.528 & 0.678 & 0.202 & 2.270 \\
\hline \multicolumn{8}{|l|}{ HCR-20V3 H1c Violence: as an adult (18 and over) } \\
\hline Violence: (18 and over) - No & & & Wald's $\chi^{2}(2)=2.953$ & 0.228 & & & \\
\hline Violence: (18 and over) - Possibly/Partially & -0.508 & 0.608 & Wald's $\chi^{2}(1)=0.700$ & 0.403 & 0.602 & 0.183 & 1.979 \\
\hline Violence: (18 and over) - Yes & 0.330 & 0.495 & Wald's $\chi^{2}(1)=0.445$ & 0.505 & 1.391 & 0.527 & 3.672 \\
\hline \multicolumn{8}{|c|}{ HCR-20V3 H2b Other antisocial behavior: as an adolescent (13-17) } \\
\hline Other antisocial behavior: (13-17) - No & & & Wald's $\chi^{2}(2)=0.756$ & 0.685 & & & \\
\hline Other antisocial behavior: (13-17) - Possibly/Partially & -0.480 & 0.579 & Wald's $\chi^{2}(1)=0.687$ & 0.407 & 0.619 & 0.199 & 1.926 \\
\hline Other antisocial behavior: (13-17) - Yes & -0.160 & 0.694 & Wald's $\chi^{2}(1)=0.053$ & 0.817 & 0.852 & 0.218 & 3.323 \\
\hline \multicolumn{8}{|c|}{ HCR-20V3 H2c Other antisocial behavior: as an adult (18 and over) } \\
\hline Other antisocial behavior: (18 and over) - No & & & Wald's $\chi^{2}(2)=3.669$ & 0.160 & & & \\
\hline Other antisocial behavior: (18 and over) - Possibly/Partially & -0.948 & 0.567 & Wald's $\chi^{2}(1)=2.793$ & 0.095 & 0.388 & 0.128 & 1.178 \\
\hline Other antisocial behavior: (18 and over) - Yes & -0.840 & 0.537 & Wald's $\chi^{2}(1)=2.448$ & 0.118 & 0.432 & 0.151 & 1.236 \\
\hline \multicolumn{8}{|l|}{ HCR-20V3 Нзb Non-intimate relationships } \\
\hline Relationships: non-intimate - No & & & Wald's $\chi^{2}(2)=8.127$ & 0.017 & & & \\
\hline Relationships: non-intimate - Possibly/Partially & 0.005 & 0.47 & Wald's $\chi^{2}(1)=0.000$ & 0.991 & 1.005 & 0.400 & 2.524 \\
\hline Relationships: non-intimate - Yes & 1.284 & 0.51 & Wald's $\chi^{2}(1)=6.325$ & 0.012 & 3.610 & 1.327 & 9.819 \\
\hline \multicolumn{8}{|l|}{ HCR-20V3 H5 Substance use } \\
\hline Substance use - No & & & Wald's $\chi^{2}(2)=14.402$ & 0.001 & & & \\
\hline Substance use - Possibly/Partially & 0.351 & 0.515 & Wald's $\chi^{2}(1)=0.465$ & 0.495 & 1.421 & 0.518 & 3.898 \\
\hline Substance use - Yes & -1.615 & 0.485 & Wald's $\chi^{2}(1)=11.092$ & 0.001 & 0.199 & 0.077 & 0.515 \\
\hline
\end{tabular}

Dichotomous dependent variable: type of group (SO vs. OO).

Abbreviations: HCR-20 V3 = Historical, Clinical and Risk Management, OO = Other offenders, OR= Odds Ratio, SO = Sex Offenders.

Bold values represent statistically significant p-values.

emotional distance, instability or conflict, manipulation of others, inappropriate sexualization and violence, particularly in nonintimate relationships. Tailored treatment programs aimed to prevent relapse in SO (Carabellese et al., 2020b; Gualtieri et al., 2020b) should address these deficits in non-intimate relationships and target psychopathic traits, specifically interpersonal and affective traits. Cognitive behavioral therapy has been found to be an effective treatment for psychopathic traits (Salekin et al., 2010). The fact that SO showed specific interpersonal deficits in the domain of non-intimate relationships suggests that a group format of treatment might be more helpful in addressing such difficulties in this population. In a group setting, the process of confronting with the experiences of other offenders might improve emotional awareness and regulation (Jennings and Sawyer, 2003; Levenson et al., 2009), and it might reduce the risk of drop-out from treatment, like for other clinical populations with impulsive traits (Pozza and Dèttore, 2017).

The result showing that SO had higher and lower levels of, respectively, interpersonal and affective deficits and antisocial behavior suggests that psychopathic traits could be differentially related to sex crimes and other types of crimes. This result appears consistent with literature data which extensively showed that sex offenders would be characterized by severe deficits in interpersonal empathy and emotion regulation (Gillespie et al., 2018; Schuler et al., 2021), while other types of offenders would show antisocial personality traits (Mazzoni et al., 2018; Azevedo et al., 2020).

The greater likelihood of a history of violence and antisocial behavior (as adolescents and adults), together with problems with substance abuse amongst $\mathrm{OO}$ as compared with $\mathrm{SO}$, is a result in line with the literature evidence (e.g., Gottfredson et al., 2008). The importance of violence during the adolescence as predictor of offending patterns in adulthood is still debated (Cardwell and Piquero, 2018), even if violent behaviors during the childhood, for example the presence of aggressions (Juon et al., 2006), seem to predict serious offending in adulthood. The link between drug use and criminal behavior has received attention from scholars (Tonry and Wilson, 1990; Bennett et al., 2008; Gottfredson et al., 2008; Liu et al., 2018).

Although several studies related to sex offenders' criminal career provided evidence of the effects of traumatic experiences during their childhood, also defined as Adverse Childhood Experiences (ACE), this relationship was not confirmed by the findings illustrated in this paper. Considering the studies which compare male sex offenders with the general population (Levenson et al., 2016; Kingston et al., 2017), sex offenders 
TABLE 4 | Results of the binary logistic model with SO/OO as outcome and the HCR2O-V3 item H8 non-intimate as predictor, in interaction with the PCL-R Factor 1 Interpersonal and affective deficits and Factor 2 Antisocial behavior; Odds Ratio and 95\% confidence interval of the Odds Ratio.

\begin{tabular}{|c|c|c|c|c|c|c|c|}
\hline \multirow[t]{2}{*}{ Predictors } & \multirow[t]{2}{*}{$\beta$} & \multirow[t]{2}{*}{ S.E. } & \multirow[t]{2}{*}{ Wald's statistic } & \multirow[t]{2}{*}{$P$} & \multirow[t]{2}{*}{ OR } & \multicolumn{2}{|c|}{ OR $95 \% \mathrm{Cl}$} \\
\hline & & & & & & $\begin{array}{l}\text { Lower } \\
\text { limit }\end{array}$ & $\begin{array}{c}\text { Upper } \\
\text { limit }\end{array}$ \\
\hline \multicolumn{8}{|l|}{$\begin{array}{l}\text { Interaction effects between } \\
\text { HCR-20V3 H3b non-intimate } \\
\text { relationships and PCL-R } \\
\text { factor } 1\end{array}$} \\
\hline $\begin{array}{l}\text { Non-intimate relationships: } \\
\text { No * PCL-R F1 Interpersonal } \\
\text { and Affective Deficits interaction }\end{array}$ & & & Wald's $\chi^{2}{ }_{(2)}=19.766$ & 0.000 & & & \\
\hline $\begin{array}{l}\text { Non-intimate relationships: } \\
\text { Possibly/Partially * PCL-R F1 } \\
\text { Interpersonal and Affective } \\
\text { Deficits interaction }\end{array}$ & 0.358 & 0.116 & Wald's $\chi^{2}(1)=9.493$ & 0.002 & 1.430 & 1.139 & 1.796 \\
\hline $\begin{array}{l}\text { Non-intimate relationships: } \\
\text { Yes * PCL-R F1 Interpersonal } \\
\text { and Affective Deficits interaction }\end{array}$ & 0.251 & 0.076 & Wald's $\chi^{2}(1)=10.824$ & 0.001 & 1.286 & 1.107 & 1.493 \\
\hline \multicolumn{8}{|l|}{$\begin{array}{l}\text { Interaction effects between } \\
\text { HCR-20V3 H3b non-intimate } \\
\text { relationships and PCL-R } \\
\text { factor } 2\end{array}$} \\
\hline $\begin{array}{l}\text { Non-intimate relationships: } \\
\text { No * PCL-R F2 Antisocial } \\
\text { Behavior interaction }\end{array}$ & & & Wald's $\chi^{2}(2)=23.521$ & 0.000 & & & \\
\hline $\begin{array}{l}\text { Non-intimate relationships: } \\
\text { Possibly/Partially * PCL-R F2 } \\
\text { Antisocial Behavior interaction }\end{array}$ & -0.533 & 0.146 & Wald's $\chi^{2}(1)=13.396$ & 0.000 & 0.587 & 0.441 & 0.781 \\
\hline $\begin{array}{l}\text { Non-intimate relationships: } \\
\text { Yes * PCL-R F2 Antisocial } \\
\text { Behavior interaction }\end{array}$ & -0.231 & 0.072 & Wald's $\chi_{(1)}^{2}=10.291$ & 0.001 & 0.794 & 0.689 & 0.914 \\
\hline
\end{tabular}

Abbreviations. HCR-20V3 = Historical, Clinical and Risk Management PCL-R = Psychopathy Checklist-Revised, SO = Sexual offenders, OO = Other offenders, $O R=$ Odds ratio. Bold values represent statistically significant $p$-values.

showed a larger odd of being victims of sexual abuse, verbal or physical abuse and emotional neglect, but also signals of adverse child-rearing experiences (incarcerated family members, parental dysfunctions, disordered familiar environment). Victimization or other traumatic experiences during the childhood, like physical, sexual and emotional abuse, were more prevalent in sex offenders than in other kinds of offenders (Lee et al., 2002; Jespersen et al., 2009; Seto and Lalumière, 2010; Reavis et al., 2013; Drury et al., 2019; Gualtieri et al., 2020a). In addition, evidence of adverse child-rearing experiences was more frequent as well, like a history of family dysfunctions or a condition of poor parenting style (Lee et al., 2002; Reavis et al., 2013; Sigre-Leirós et al., 2016).

Many reasons can explain the divergent findings reported in this paper. First, the methodological issues that affect this research topic. The review of McMillan et al. (2008), specifically carried out on sexual offenders against children, pointed out a series of problems related to the temporal relationship between a putative risk factor and sexual perpetration, the effects of other variables, and the complexity in modeling developmental phenomena.

Secondarily, this lack of evidence may be due to the measurement scale administered to the participants, in particular the HCR-20 V3 used to assess the risk factors. The Historical Clinical Risk Management-20 (HCRS-20) has been criticized for its low field validity in clinical forensic psychiatry settings (Jeandarme et al., 2017; Tully, 2017). On the contrary, other studies supported the psychometric validity and the clinical utility of the scale (Judges et al., 2016), highlighting that the scoring subjectivity of the scale did not impair its reliability, above all for the HCR-20 V3 historical scale (Rufino et al., 2011).

A third problem can be associated to the method used by this scale to assess the risk factors, which are described by a wide variety of lifetime events such as trauma or victimization related to parental and non-parental sexual abuse during childhood/adolescence, witnessing of domestic violence, bullying, or lifetime interpersonal victimization. As much heterogeneity of events is also listed to measure the presence of adverse child-rearing experiences (overly rigid parenting styles, unstable family relations, conviction of parents before the subject reached 10 years of age, death of a parent during childhood or adolescence, separation from parents before 17 years of age, parental substance abuse). Probably, this wide set of experiences describing a single indicator can reduce its specificity in detecting the risk factors. 
Some limitations of the study should be pointed out. Firstly, the recruitment of the sample might be subjected to a bias as this process took place in agreement with the Penitentiary Administration of the Ministry of Justice. The first stage of recruitment was carried out exclusively by the prison administration, which asked the prisoners if they were interested in participating to a preliminary meeting with the researchers. On that occasion, the researchers presented the project in detail and asked the prisoners for the informed consent. However, other information that could have been useful for the purpose of the research was not provided to the researchers by the prison administration. In particular, no data were provided about the specific types of crime of the OO group or how many of both the groups of offenders were recidivists. However, it was wellestablished that those prisoners belonging to the group of SO did not commit any other crimes than sexual ones.

Secondly, the cross-sectional design did not allow us to draw firm conclusion about the role of the risk factors in the likelihood of being SO or OO, particularly in the risk of recidivism. Future research should use a longitudinal design to ascertain problems in non-intimate relationships and whether interpersonal/affective deficits can predict a higher risk of recidivism in sexual crime as compared with the risk of recidivism in other types of crime.

Another relevant limitation concerns the fact that individuals with a psychiatric history were excluded. This aspect reduced the external validity of this research. The findings observed in the present sample may be applied to a minority of the SO population. In fact, SO with no other criminal record and no lifetime psychiatric diagnosis typically represent only a small proportion of SO that is lower than $20 \%$, as the lack of psychiatric comorbidities is generally observed in a $7-15 \%$ proportion of the SO population (e.g., Raymond et al., 1999; Dunsieth et al., 2004). Future studies should also include individuals with lifetime psychiatric disorders and control the effect of the presence of psychiatric conditions in the risk of being $\mathrm{SO}$ or OO, particularly severe psychiatric disorders such as psychosis/bipolar and personality disorders (Van Wijk et al., 2007; Coluccia et al., 2015; Chen et al., 2016; Eastman et al., 2019). However, the role of psychiatric disorders in the risk of violence has been questioned as a dimensional approach is considered more informative (Graz et al., 2009). Finally, an area that deserves further exploration regards the moderator effect of protective factors in the relation between life events and crime type. It would be interesting to examine whether certain protective factors such as the capacity to forgive oneself (Barcaccia et al., 2019) could protect the individual from the criminal behavior.

\section{REFERENCES}

Andersen, H. S., Sestoft, D., Lillebaek, T., Mortensen, E. L., and Kramp, P. (1999). Psychopathy and psychopathological profiles in prisoners on remand. Acta Psychiatr. Scand. 99, 33-39. doi: 10.1111/j.1600-0447.1999.tb05382.x

Azevedo, J., Vieira-Coelho, M., Castelo-Branco, M., Coelho, R., and FigueiredoBraga, M. (2020). Impulsive and premeditated aggression in male

\section{CONCLUSION}

The role of life events as risk factors for sexual crime is a complex and long-debated topic in criminological research. The present study is the first contribution which compared SO and OO on the risk factors assessed by the HCR-20V3 and explored the role of psychopathic traits as moderators of the relation between specific life events and the risk of having committed sexual crime or other types of crime. The present findings shed further light on this issue showing the role of deficient nonintimate relationships in predicting the criminal career of sex offenders, and suggesting that specific psychopathic traits, i.e., interpersonal/affective deficits, but not antisocial behavior, can moderate the relation between a history of problems in nonintimate relationships and sexual crime.

\section{DATA AVAILABILITY STATEMENT}

The original contributions presented in the study are included in the article/Supplementary Material, further inquiries can be directed to the corresponding author.

\section{ETHICS STATEMENT}

The studies involving human participants were reviewed and approved by Director of Penitentiary Administration Department of Ministry of Justice. The patients/participants provided their written informed consent to participate in this study.

\section{AUTHOR CONTRIBUTIONS}

FF performed the statistical analysis. AP interpreted the results of the analyses and wrote the manuscript with support from FF, $\mathrm{FuC}$, and FeC. AS and GS took care of the bibliographic research. $\mathrm{FuC}$ was the corresponding author. GM collected the data. GG contributed to the bibliographic research. FeC conceived of the presented idea and collected the data. RC and AC performed a general review. All authors contributed to the article and approved the submitted version.

\section{SUPPLEMENTARY MATERIAL}

The Supplementary Material for this article can be found online at: https://www.frontiersin.org/articles/10.3389/fpsyg. 2021.600370/full\#supplementary-material

offenders with antisocial personality disorder. PLoS One 15:e0229876. doi: 10.1371/journal.pone.0229876

Barcaccia, B., Pallini, S., Pozza, A., Milioni, M., Baiocco, R., Mancini, F., et al. (2019). Forgiving adolescents: far from depression, close to well-being. Front. Psychol. 10:1725. doi: 10.3389/fpsyg.2019.01725

Bennett, T., Holloway, K., and Farrington, D. (2008). The statistical association between drug misuse and crime: a meta-analysis. 
Aggress. Violent Behav. 13, 107-118. doi: 10.1016/j.avb.2008. 02.001

Burton, D. L. (2008). An Exploratory Evaluation of the Contribution of Personality and Childhood Sexual Victimization to the Development of Sexually Abusive Behavior. Sex. Abuse 20, 102-115. doi: 10.1177/107906320831 5352

Campbell, M. A., French, S., and Gendreau, P. (2009). The prediction of violence in adult offenders: a meta-analytic comparison of instruments and methods of assessment. Crim. Justice Behav. 36, 567-590. doi: 10.1177/009385480933 3610

Campobasso, C., Colonna, M., Carabellese, F., Grattagliano, I., Candelli, C., Morton, R. J., et al. (2009). A serial killer of elderly women: analysis of a multi-victim homicide investigation. Forensic Sci. Int. 185, 7-11. doi: 10.1016/j. forsciint.2008.12.023

Carabellese, F., Felthous, A. R., Mandarelli, G., Montalbò, D., La Tegola, D., Parmigiani, G., et al. (2020a). Women and Men who Committed Murder: male/Female Psychopathic Homicides. J. Forensic Sci. 65, 1619-1626. doi: 10. $1111 / 1556-4029.14450$

Carabellese, F., Urbano, M., Carabellese, F., Gualtieri, G., Pozza, A., Ferretti, F., et al. (2020b). Il trattamento giudiziario del sex offender: vecchi limiti, nuove opportunità. Ital. J. Criminol. 14, 229-241.

Carabellese, F., Rocca, G., Candelli, C., La Tegola, D., and Birkhoff, J. (2012). La gestione degli autori di reati sessuali tra psicopatologia e rischio di recidiva. Prospettive trattamentali. Rassegna Ital. di Criminol. 2, 70-83.

Carabellese, F., Vinci, F., and Catanesi, R. (2008). Compatibility Between Mental Disorder and Mental Capacity: analysis of a Particolar Case of Group Sexual Homicide. J. Forensic Sci. 53, 1450-1454. doi: 10.1111/j.1556-4029.2008.0 0897

Cardwell, S. M., and Piquero, A. R. (2018). Does Violence in Adolescence Differentially Predict Offending Patterns in Early Adulthood? Int. J. Offender Ther. Comp. Criminol. 62, 1603-1628. doi: 10.1177/0306624x16688978

Caretti, V., Ciappi, S., Scarpa, F., Castelletti, L., Catanesi, R., Carabellese, F., et al. (2019). HCR 20-3 Checklist per la valutazione del rischio di recidiva di un crimine violento. Adattamento Italiano. Firenze: Hogrefe.

Caretti, V., Manzi, G. S., Schimmenti, A., and Seragusa, L. (2011). PCL-R. Hare Psychopathy Checklist Revised. Firenze: Giunti.

Cartwright, J. K., Desmarais, S. L., Hazel, J., Griffith, T., and Azizian, A. (2018). Predictive validity of HCR-20, START, and static-99R assessments in predicting institutional aggression among sexual offenders. Law Hum. Behav. 42, 13-25. doi: $10.1037 / \mathrm{lhb} 0000263$

Catanesi, R., Mandarelli, G., Ferracuti, S., Valerio, A., and Carabellese, F. (2019). The new residential forensic psychiatric system (REMS): a one-year population study. Ital. J. Criminol. 13, 7-23. doi: 10.7347/RIC.NS2019

Chen, Y. Y., Chen, C. Y., and Hung, D. L. (2016). Assessment of psychiatric disorders among sex offenders: prevalence and associations with criminal history. Crim. Behav. Ment. Health 26, 30-37. doi: 10.1002/cbm. 1926

Coluccia, A., Ferretti, F., Fagiolini, A., and Pozza, A. (2015). Incidenza e fattori di rischio per disturbi psicotici nelle popolazioni migranti in Europa: una meta-analisi di studi trasversali. Ital. J. Criminol. 9, 29-39.

Coluccia, A., Pozza, A., Ferretti, F., Carabellese, F., Masti, A., and Gualtieri, G. (2020). Online romance scams: relational dynamics and psychological characteristics of the victims and scammers. A scoping review. Clin. Pract. Epidemiol. Ment. Health 16, 24-35. doi: 10.2174/174501790201601 0024

Douglas, K. S., Hart, S. D., Webster, C. D., and Belfrage, H. (2013). HCR-20V3. Assessing Risk for Violence. Burnaby: Mental Health, Law, and Policy Institute, Simon Fraser University.

Drury, A. J., Elbert, M. J., and DeLisi, M. (2019). Childhood sexual abuse is significantly associated with subsequent sexual offending: new evidence among federal correctional clients. Child Abuse Negl. 95:104035. doi: 10.1016/j.chiabu. 2019.104035

Dunsieth, N. W. Jr., Nelson, E. B., Brusman-Lovins, L. A., Holcomb, J. L., Beckman, D., Weldge, J. A., et al. (2004). Psychiatric and legal features of 113 men convicted of sexual offenses. J. Clin. Psychiatry 65, 293-300. doi: 10.4088/jcp. v65n0302

Eastman, O., Craissati, J., and Shaw, J. (2019). Young adult sexual offenders with emerging personality disorders: developmental and offence-related characteristics and treatment engagement. J. Sex. Aggress. 25, 105-115. doi: 10.1080/13552600.2018.155 1501

Eher, R., Rettenberger, M., and Turner, D. (2019). The prevalence of mental disorders in incarcerated contact sexual offenders. Acta Psychiatr. Scand. 139, 572-581. doi: 10.1111/acps.13024

Gannon, T. A., Olver, M. E., Mallion, J. S., and James, M. (2019). Does specialized psychological treatment for offending reduce recidivism? A meta-analysis examining staff and program variables as predictors of treatment effectiveness. Clin. Psychol. Rev. 73:101752. doi: 10.1016/j.cpr.2019.10 1752

Gillespie, S. M., Garofalo, C., and Velotti, P. (2018). Emotion regulation, mindfulness, and alexithymia: specific or general impairments in sexual, violent, and homicide offenders? J. Crim. Justice 58, 56-66. doi: 10.1016/j.jcrimjus.2018. 07.006

Gottfredson, D. C., Kearley, B. W., and Bushway, S. D. (2008). Substance use, drug treatment, and crime: an examination of intra-individual variation in a drug court population. J. Drug Issues 38, 601-630. doi: 10.1177/00220426080380 0211

Grann, M., Langstrom, N., Tengstrom, A., and Stalenheim, E. G. (1998). Reliability of File-Based Retrospective Ratings of Psychopathy With the PCL-R. J. Pers. Assess. 70, 416-426. doi: 10.1207/s15327752jpa7003_2

Graz, C., Etschel, E., Schoech, H., and Soyka, M. (2009). Criminal behaviour and violent crimes in former inpatients with affective disorder. J. Affec. Disord. 117, 98-103. doi: 10.1016/j.jad.2008.12.007

Gualtieri, G., Ferretti, F., Masti, A., Pozza, A., and Coluccia, A. (2020a). Posttraumatic Stress Disorder in Prisoners' Offspring: a Systematic Review and Meta-analysis. Clin. Pract. Epidemiol. Ment. Health 16, 36-45. doi: 10.2174/ 1745017902016010036

Gualtieri, G., Traverso, S., Pozza, A., Ferretti, F., Carabellese, F., Gusinu, R., et al. (2020b). Clinical risk management in High-Security Forensic Psychiatry Residences. Protecting patients and health professionals: perspectives and critical issues of the Law 81/2014. Clin. Ter. 171, e97-e100.

Hanson, R. K., Bourgon, G., Helmus, L., and Hodgson, S. (2009). A Meta-analysis of the Effectiveness of Treatment for Sexual Offenders: Risk, Need, and Responsivity. Ottawa: Corrections Research, Public Safety Canada.

Hanson, R. K., and Morton-Bourgon, K. E. (2005). The characteristics of persistent sexual offenders: a meta-analysis of recidivism studies. J. Consult. Clin. Psychol. 73, 1154-1163. doi: 10.1037/0022-006X.73.6. 1154

Hare, R. D., Harpur, T. J., and Hakstian, A. R. (1989). Two-factor conceptualization of psychopathy: construct validity and assessment implications. Psychol. Assess. 1, 6-17. doi: 10.1037/1040-3590.1.1

Hare, R. D., and Neumann, C. N. (2006). "The PCL-R Assessment of Psychopathy: development, Structural Properties, and New Directions," in Handbook of Psychopathy, ed. C. Patrick (New York: Guilford), 58-88.

Ismail, G., and Looman, J. (2018). Field Inter-Rater Reliability of the Psychopathy Checklist-Revised. Int. J. Offender Ther. Comp. Criminol. 62, 468-481. doi: 10.1177/0306624X1665 2452

Jeandarme, I., Pouls, C., De Laender, J., Oeic, T. I., and Bogaertsd, S. (2017). Field validity of the HCR-20 in forensic medium security units in Flanders. Psychol. Crime Law. 23, 305-322. doi: 10.1080/1068316x.2016.125 8467

Jennings, J. L., and Sawyer, S. (2003). Principles and techniques for maximizing the effectiveness of group therapy with sex offenders. Sex. Abuse 15, 251-267. doi: $10.1177 / 107906320301500403$

Jespersen, A. F., Lalumière, M. L., and Seto, M. C. (2009). Sexual abuse history among adult sex offenders and non-sex offenders: a metaanalysis. Child Abuse Negl. 33, 179-192. doi: 10.1016/j.chiabu.2008.0 7.004

Judges, R., Egan, V., and Broad, G. (2016). Critique of the Historical Clinical Risk-20, Version 3, Risk Assessment Instrument. J. Forensic Psychol. Pract. 16, 304-320. doi: 10.1080/15228932.2016.1196102

Juon, H. S., Doherty, E. E., and Ensminger, M. E. (2006). Childhood Behavior and Adult Criminality: cluster Analysis in a Prospective Study of African Americans. J. Quant. Criminol. 22, 193-214. doi: 10.1007/s10940-006-9 008-9 
Jüriloo, A., Lauerma, H., Holmalahti, T., Tyni, S., Aarnio, J., Viitanen, P., et al. (2013). Psychopathic traits in a representative sample of Finnish male prisoners. Nord. J. Psychiatry 68, 117-122. doi: 10.3109/08039488.2013.78 0259

Kennealy, P. J., Skeem, J. L., Walters, G. D., and Camp, J. (2010). Do core interpersonal and affective traits of PCL-R psychopathy interact with antisocial behavior and disinhibition to predict violence? Psychol. Assess. 22, 569-580. doi: 10.1037/a001 9618

Kimonis, E. R., Skeem, J. L., Cauffman, E., and Dmitrieva, J. (2011). Are secondary variants of juvenile psychopathy more reactively violent and less psychosocially mature than primary variants? Law Hum. Behav. 35, 381-391. doi: 10.1007/ s10979-010-9243-3

Kingston, D. A., Graham, F. J., and Knight, R. A. (2017). Relations Between SelfReported Adverse Events in Childhood and Hypersexuality in Adult Male Sexual Offenders. Arch Sex. Behav. 46, 707-720. doi: 10.1007/s10508-016-0 873-5

Kraanen, F. L., and Emmelkamp, P. M. G. (2011). Substance misuse and substance use disorders in sex offenders: a review. Clin. Psychol. Rev. 31, 478-489. doi: 10.1016/j.cpr.2010.11.006

Lee, J. K. P., Jackson, H. J., Pattison, P., and Ward, T. (2002). Developmental risk factors for sexual offending. Child Abuse Negl. 26, 73-92. doi: 10.1016/S01452134(01)00304-0

Leistico, A. R., Salekin, R. T., De Coster, J., and Rogers, R. (2008). A large-scale meta-analysis relating the hare measures of psychopathy to antisocial conduct. Law Hum. Behav. 32, 28-45. doi: 10.1007/s10979-0079096-6

Levenson, J. S., Macgowan, M. J., Morin, J. W., and Cotter, L. P. (2009). Perceptions of sex offenders about treatment: satisfaction and engagement in group therapy. Sex. Abuse 21, 35-56. doi: 10.1177/107906320832 6072

Levenson, J. S., Willis, G. M., and Prescott, D. S. (2016). Adverse Childhood Experiences in the Lives of Male Sex Offenders: implications for TraumaInformed Care. Sex. Abuse 28, 340-359. doi: 10.1177/107906321453 5819

Liu, L., Chui, W. H., and Chen, Y. (2018). Violent and Non-Violent Criminal Behavior among Young Chinese Drug Users: a Mixed Methods Study. Int. J. Env. Res. Public Health 15:432. doi: 10.3390/ijerph1503 0432

Mandarelli, G., Carabellese, F., Parmigiani, G., Bernardini, F., Pauselli, L., Quartesan, R., et al. (2017). Treatment decision-making capacity in nonconsensual psychiatric treatment: a multicentre study. Epidemiol. Psychiatr. Sci. 9, 1-8.

Mazzoni, G. P., Contena, B., Fanciullacci, S., and Pozza, A. (2018). Analisi comparativa dei profili di personalità di pazienti affetti da disturbo borderline e detenuti con diagnosi di disturbo antisociale di personalità ottenuti tramite l'MMPI-2. Riv. Psichiatr. 53, 267-273. doi: 10.1708/3000.3 0006

McMillan, D., Hastings, R. P., Salter, D. C., and Skuse, D. H. (2008). Developmental risk factor research and sexual offending against children: a review of some methodological issues. Arch. Sex. Behav. 37, 877-890. doi: 10.1007/s10508-0079193-0

Myers, W. C., Marrero, L., and Herkov, M. J. (2005). "Forensic Psychiatry and Forensic Psychology," in Encyclopedia of Forensic and Legal Medicine, ed. J. Payne-James (Cambridge: Elsevier Academic Press), $444-451$.

Ometto, M., de Oliveira, P. A., Milioni, A. L., Dos Santos, B., Scivoletto, S., Busatto, G. F., et al. (2016). Social skills and psychopathic traits in maltreated adolescents. Eur. Child Adolesc. Psychiatry 25, 397-405. doi: 10.1007/s00787-0150744-y

Porter, S., Newman, E., Tansey, L., and Quayle, E. (2015). Sex offending and social anxiety: a systematic review. Aggress. Violent Behav. 24, 42-60. doi: 10.1016/j. avb.2015.04.005

Pozza, A., Coluccia, A., Gualtieri, G., Carabellese, F., Masti, A., and Ferretti, F. (2020). Post-traumatic stress disorder secondary to manic episodes with hypersexuality in bipolar disorder: a case study of forensic psychotherapy. Clin. Neuropsychiatry 17, 181-188.
Pozza, A., Coluccia, A., Kato, T., Gaetani, M., and Ferretti, F. (2019). The 'Hikikomori' syndrome: worldwide prevalence and co-occurring major psychiatric disorders: a systematic review and meta-analysis protocol. BMJ Open 9:e025213. doi: 10.1136/bmjopen-2018-02 5213

Pozza, A., and Dèttore, D. (2017). Drop-out and efficacy of group versus individual cognitive behavioural therapy: what works best for ObsessiveCompulsive Disorder? A systematic review and meta-analysis of direct comparisons. Psychiatry Res. 258, 24-36. doi: 10.1016/j.psychres.2017.0 9.056

Rasmussen, L. A. (2012). - Victim and Victimizer: the Role of Traumatic Experiences as Risk Factors for Sexually Abusive Behavior. Isr. J. Psychiatry Relat. Sci. 49, 270-279.

Raymond, N. C., Coleman, E., Ohlerking, F., Christenson, G. A., and Miner, M. (1999). Psychiatric comorbidity in pedophilic sex offenders. Am. J. Psychiatry 156, 786-788.

Reavis, J. A., Looman, J., Franco, K. A., and Rojas, B. (2013). Adverse childhood experiences and adult criminality: how long must we live before we possess our own lives? Perm. J. 17, 44-48. doi: 10.7812/TPP/1 2-072

Rufino, K. A., Boccaccini, M. T., and Guy, L. S. (2011). Scoring subjectivity and item performance on measures used to assess violence risk: the PCL-R and HCR-20 as exemplars. Assessment 18, 453-463. doi: 10.1177/107319111037 8482

Salekin, R. T., Worley, C., and Grimes, R. D. (2010). Treatment of psychopathy: a review and brief introduction to the mental model approach for psychopathy. Behav. Sci. Law 28, 235-266. doi: 10.1002/bsl. 928

Schimmenti, A., Carabellese, F. F., and Caretti, V. (2020). "Child maltreatment and psychopathy," in The International Handbook of Psychopathic Disorders and the Law, Volume I: Diagnosis and Treatment, Second Edition, eds A. R. Felthous and H. Saß (Chichester: John Wiley \& Sons, Ltd).

Schraft, C. V., Kosson, D. S., and McBride, C. K. (2013). Exposure to violence within home and community environments and psychopathic tendencies in detained adolescents. Crim. Justice Behav. 40, 1027-1043. doi: 10.1177/009385481348 6887

Schuler, M., Mohnke, S., Amelung, T., Dziobek, I., Borchardt, V., Gerwinn, H., et al. (2021). Empathy in paedophilia and sexual offending against children: a longitudinal extension. J. Sex. Aggress. 1-18. doi: 10.1080/13552600.2021. 1931721

Seto, M. C., and Lalumière, M. L. (2010). What is so special about male adolescent sexual offending? A review and test of explanations through meta-analysis. Psychol. Bull. 136, 526-575. doi: 10.1037/a001 9700

Sevecke, K., Franke, S., Kosson, D., and Krischer, M. (2016). Emotional dysregulation and trauma predicting psychopathy dimensions in female and male juvenile offenders. Child Adolesc. Psychiatry Ment. Health 10:43. doi: 10. 1186/s13034-016-0130-7

Sigre-Leirós, V., Carvalho, J., and Nobre, P. J. (2016). Early parenting styles and sexual offending behavior: a comparative study. Int. J. Law Psychiatry 46, 103-109. doi: 10.1016/j.ijlp.2016.02.042

Somma, A., Fossati, A., Carabellese, F., Santoro, G., Schimmenti, A., Caretti, V., et al. (2020). Dysfunctional Personality Traits and Demographic Variables Associated with Violence Risk in Male Sexual Offenders: a Study on Italian Adult Inmates. J. Forensic Psychiatry Psychol. 32, 242-260. doi: 10.1080/14789949.2020.185 7425

Tonry, M., and Wilson, J. Q. (1990). Drugs and Crime. Chicago: University of Chicago Press.

Tully, J. (2017). HCR-20 shows poor field validity in clinical forensic psychiatry settings. Evid. Based Ment. Health 20, 95-96. doi: 10.1136/eb-2017-10 2745

Van Wijk, A. P., Blokland, A. A. J., Duits, N., Vermeiren, R. R. J. M., and Harkink, J. (2007). Relating psychiatric disorders, offender and offence characteristics in a sample of adolescent sex offenders and non-sex offenders. Crim. Behav. Ment. Health 17, 15-30. doi: 10.1002/cbm. 628 
Wong, S. C. P., and Olver, M. E. (2016). "Risk reduction treatment of psychopathy and applications to mentally disordered offenders," in Violence in Psychiatry, eds K. D. Warburton and S. M. Stahl (Cambridge: Cambridge University Press), 32 3-331.

Yang, M., Wong, S., and Coid, J. (2010). The efficacy of violence prediction: a metaanalytic comparison of nine risk assessment tools. Psychol. Bull. 136, 740-767. doi: $10.1037 / \mathrm{a} 0020473$

Yates, P. M. (2013). Treatment of sexual offenders: research, best practices, and emerging models. Int. J. Behav. Consult. Ther. 8, 89-95. doi: 10.1037/h0100989

Conflict of Interest: The authors declare that the research was conducted in the absence of any commercial or financial relationships that could be construed as a potential conflict of interest.
Publisher's Note: All claims expressed in this article are solely those of the authors and do not necessarily represent those of their affiliated organizations, or those of the publisher, the editors and the reviewers. Any product that may be evaluated in this article, or claim that may be made by its manufacturer, is not guaranteed or endorsed by the publisher.

Copyright (c) 2021 Ferretti, Pozza, Carabellese, Schimmenti, Santoro, Mandarelli, Gualtieri, Carabellese, Catanesi and Coluccia. This is an open-access article distributed under the terms of the Creative Commons Attribution License (CC BY). The use, distribution or reproduction in other forums is permitted, provided the original author(s) and the copyright owner(s) are credited and that the original publication in this journal is cited, in accordance with accepted academic practice. No use, distribution or reproduction is permitted which does not comply with these terms. 